\title{
STRATEGI PEMASARAN PRODUK IKAN CAKALANG ASAP (STUDI KASUS: UKM FROZEN SEAS)
}

\author{
MARKETING STRATEGY FOR SMOKED SKIPJACK FISH PRODUCTS \\ (CASE STUDY: FROZEN SEAS SME)
}

\author{
Meilya Suzan Triyastuti*, Daniel H. Ndahawali, Hetty M.P. Ondang \\ Politeknik Kelautan dan Perikanan Bitung, Jl. Tandurusa, Aertembaga Dua, Aertembaga, Aertembaga \\ Dua, Bitung, Kota Bitung, Sulawesi Utara
}

Teregistrasi I tanggal: 05 Februari 2021; Diterima setelah perbaikan tanggal: 28 Mei 2021; Disetujui terbit tanggal: 31 Mei 2021

\begin{abstract}
ABSTRAK
Penelitian ini bertujuan untuk merumuskan strategi pemasaran ikan cakalang asap di UKM Frozen Seas dengan mengidentifikasi faktor internal maupun eksternal di UKM Frozen Seas. Penelitian dilakukan di UKM Frozen seas, Bitung dengan menganalisis faktor internal dan eksternal yang berdampak pada strategi pemasaran ikan cakalang asap. Hasil penelitian menunjukkan bahwa strategi pemasaran yang diperlukan diantaranya kerjasama dengan perusahaan untuk mendapatkan bahan baku dan produk yang berkualitas; diferensiasi pengemasan yg ramah lingkungan, rasa dan harga yg murah; penerapan teknologi pengasapan yang efektif dan efisien terhadap peningkatan kandungan nutrisi ikan; informasi kandungan gizi pada kemasan, menambah pasar dengan kerjasama dengan pihak terkait.
\end{abstract}

Kata kunci: cakalang, ikan, pemasaran

\begin{abstract}
Frozen seas SMEs need the right marketing strategy so that smoked skipjack products can compete in the digital era. This study aims to formulate a marketing strategy for smoked skipjack tuna in Frozen seas UKM by identifying internal and external factors in Frozen seas UKM. The research method used in this research is the descriptive method. The research data were obtained by conducting observations, documentation, and interviews. The research was conducted at UKM Frozen Seas by analyzing internal and external factors that had an impact on the marketing strategy of smoked skipjack tuna. The results show that there is a need for a marketing strategy to optimize product sales and increase profits. Therefore, it is necessary to have a marketing strategy in the SME Frozen Seas which is needed including cooperation with companies to obtain quality raw materials and products; differentiation of environmentally friendly packaging, taste and low price; application of effective and efficient smoking technology to increase the nutritional content of fish; information on nutritional content on the packaging, adding to the market in collaboration with related parties.
\end{abstract}

Keywords: skipjack, fish, marketing

Korespondensi penulis:
*Email: meilya.striyastuti@gmail.com

DOI: http://dx.doi.org/10.15578/plgc.v2i2.9727 


\section{PENDAHULUAN}

Kelautan dan perikanan merupakan salah satu potensi sumberdaya alam melimpah dan mendapatkan kepedulian yang penting di Indonesia. Sumberdaya penangkapan ikan laut di Indonesia sekitar 6,5 juta ton/tahun (Sutardjo, 2014). Potensi sumber daya ikan terbesar di Indonesia pada golongan pelagis besar diantaranya tuna, tongkol, cakalang. Hasil perikanan tuna, tongkol, cakalang mempunyai peranan penting di dunia. Lebih dari $16 \%$ suplai hasil tangkapan ikan tuna, tongkol, cakalang di Indonesia untuk dunia (Firdaus, 2018).

Menurut Supriana et al. (2014) wilayah sirkulasi ikan pelagis besar di Indonesia diantaranya perairan Maluku, perairan Sulawesi, perairan Hindia, selatan Jawa, utara Sulawesi, dan lain lain. Kota Bitung, Provinsi Sulawesi Utara yaitu daerah hasil produksi perikanan tangkap ikan Tuna serta Cakalang (Statistik Perikanan Tangkap Indonesia, 2015)). Lokasi Kota Bitung merupakan kota penghasil perikanan di provinsi Sulawesi Utara. Bitung merupakan kota bahari yang berkaitan pada aktivitas yang berhubungan dengan perikanan pesisir. Pelabuhan Internasional di Bitung yang mempunyai potensi perikanan untuk menambah devisa negara di kawasan Asia Pasifik (Pramana et al., 2017; Sulistiana et al., 2018). Bitung merupakan produksi perikanan tangkan ikan tuna dan cakalang.

Pemerintah kota Bitung mendorong peningkatan produktivitas pelaku usaha dengan meminjamkan dana Usaha Kecil Menengah (UKM) dan pelatihan peningkatan nilai produk yang dapat mempengaruhi faktor-faktor peningkatan kinerja usaha tersebut. Usaha kecil menengah pada kinerja derajat kesuksesan masih rendah, maka diperlukan aspek untuk menentukan tingkat kejayaan perkembangan UKM. Karakteristik dan kompetensi wirausaha merupakan bukti keberhasilan usaha kecil, namun jika lingkungan usaha semakin dinamis dan persaingan yang semakin meningkat maka keberhasilan usaha tidak terlepas dari peran strategi (Sarwoko, 2017). Li et al. (2009) mengatakan jika strategi kewirausahaan berhubungan kinerja usaha. Selain itu, kinerja sektor UKM ada dua faktor utama yaitu eksternal dan internal. Internal meliputi aspek SDM; aspek keuangan, aspek teknis produksi; dan aspek pemasaran. Sedangkan eksternal terdiri dari kebijakan pemerintah, aspek sosial budaya dan ekonomi, serta peranan lembaga (Riyanto, 2018). Dengan demikian, perlu dilakukan analisis aspek lingkungan internal dan eksternal untuk mengetahui peningkatan UKM di Bitung.

UKM Frozen seas telah mendapatkan No P-IRT (Produk Industri Rumah Tangga) dan No MUI (Majelis Ulama Indonesia). Izin produksi dan sertifikasi halal tersebut merupakan prestasi untuk pemasaran cakalang asap. Namun, pemasaran langsung (direct marketing) di awal masa pandemi COVID-19 ini berpengaruh pada omset ikan cakalang asap. UKM Frozen seas memerlukan strategi pemasaran yang tepat agar produk cakalang asap dapat bersaing di era digital. Penelitian ini bertujuan untuk merumuskan strategi pemasaran ikan cakalang asap di UKM Frozen seas dengan mengidentifikasi faktor internal maupun eksternal di UKM Frozen seas.

\section{BAHAN DAN METODE}

Pelaksanaan penelitian ini dilakukan pada UKM Frozen seas yang merupakan produsen cakalang asap higienis dalam jumlah cukup besar di Kota Bitung. UKM Frozen seas berlokasi di Perum Rizky Permata Indah Blok F No. 7 Jl. Aer Ujang, RT.13, Girian Permai, Girian, Kota Bitung. Pelaksanaan penelitian dilakukan pada bulan Juli hingga Desember 2020. 
Metode penelitian ini menggunakan metode studi kasus di UKM Frozen seas. Sumber data terdiri dari data primer dan data sekunder. Teknik pengumpulan data primer dilakukan dengan beberapa metode diantaranya observasi, wawancara, dan dokumentasi.

a. Observasi: metode pengumpulan data dengan melakukan pengamatan secara langsung terkait pembuatan ikan cakalang asap di UKM Frozen Seas.

b. Wawancara: metode penelitian yang dilakukan dengan tanya jawab secara langsung dengan pemilik UKM Frozen Seas.

c. Dokumentasi: metode penelitian yang didapatkan secara tertulis yang berbentuk pustaka pada pengemasan ikan cakalang asap.

Data sekunder diperoleh melalui media sosial UKM Frozen Seas. Menurut Faradizza dkk. (2019), menyatakan bahwa menganalisis data yang sudah diperoleh dengan metode deskriptif, melakukan wawancara dengan menjelaskan deskripsi dan keterangan menggunakan bahasa penulis sendiri, secara terstruktur dan mudah dipahami sesuai dengan data yang didapatkan. Penelitian kualitatif ini menggunakan analisis internal, analisis eksternal, dan analisis SWOT.

\section{HASIL DAN BAHASAN HASIL}

Berdasarkan penelitian pada pemilik UKM Forzen Seas, maka diperoleh hasil penelitian dengan menganalisis faktor internal, faktor eksternal dan analisis SWOT. Berikut ini hasil penelitian yang telah didapatkan:

\section{Analisis eksternal}

Analisis eksternal dilakukan dengan mengidentifikasi faktor eksternal dengan menggunakan analisis PEST dan bauran pemasaran. Faktor PEST (Politik, Ekonomi, Sosial Budaya dan Teknologi) mempunyai pengaruh global sehingga mempengaruhi UKM dalam menjalankan usahanya. Faktor bauran Pemasaran diantaranya produk, harga, tempat, promosi.

\section{Analisis internal}

Analisis internal ini dilakukan dengan mengidentifikasi faktor internal diantarannya:

a) Bahan baku

b) Produk ikan cakalang asap telah mendapatkan label halal MUI. dan izin P-IRT.

c) Pemasaran ikan cakalang asap belum optimal.

d) Manajemen UKM Frozen seas.

e) Permodalan.

f) Infrastruktur berkaitan dengan Unit Pengolahan Ikan.

\section{Analisis SWOT}

Analisis SWOT ini ditunjukkan pada Tabel 1. Total skor pada matrks evalusi faktor strategis internal yang ditunjukkan Tabel 2 sebesar 3,18. Hal ini menunjukkan kondsi internal UKM Frozen seas mempunyai kekuatan untuk mencegah serta menyelesaikan kelemahan yang ada.

Tabel 3 menunjukkan total skor matriks evaluasi faktor strategis eksternal sebesar 3,05. Hal ini menunjukkan bahwa UKM Frozen seas mampu menyelesaikan ancaman yang terjadi menggunakan peluang yang tersedia (Gambar 1). 
Tabel 1 . Analisis SWOT Strategi Pemasaran Produk Ikan Cakalang Asap

Table 1. SWOT Analysis of Smoked Skipjack Fish Product Marketing Strategy

\begin{tabular}{|c|c|c|c|}
\hline \multicolumn{2}{|r|}{ Kekuatan } & \multicolumn{2}{|r|}{ Kelemahan } \\
\hline S1 & $\begin{array}{l}\text { Bahan baku melimpah dan } \\
\text { berkualitas }\end{array}$ & W1 & $\begin{array}{l}\text { Fluktuasi hasil tangkapan yang } \\
\text { musiman pada ikan cakalang }\end{array}$ \\
\hline $\mathrm{S} 2$ & $\begin{array}{l}\text { Jarak tempuh bahan baku, tempat } \\
\text { produksi dan pemasaran yang dekat }\end{array}$ & W2 & $\begin{array}{l}\text { Belum optimal pemasaran produk di } \\
\text { media sosial }\end{array}$ \\
\hline S3 & $\begin{array}{l}\text { Kandungan nutrisi bahan baku yang } \\
\text { bermanfaat bagi tubuh }\end{array}$ & W3 & Belum optimal promosi produk \\
\hline S4 & Potensi ekspor produk tinggi & W4 & $\begin{array}{l}\text { Promosi melalui online belum } \\
\text { optimal }\end{array}$ \\
\hline S5 & $\begin{array}{l}\text { Hubungan yang baik antara sektor } \\
\text { dan non pemerintah }\end{array}$ & & \\
\hline & Peluang & & Ancaman \\
\hline $\mathrm{O} 1$ & $\begin{array}{l}\text { Peningkatan konsumsi ikan pada } \\
\text { masyarakat }\end{array}$ & T1 & Fluktuasi harga ikan cakalang \\
\hline $\mathrm{O} 2$ & Pengolahan ikan yang lebih variatif & $\mathrm{T} 2$ & Branding yang menarik \\
\hline $\mathrm{O} 3$ & $\begin{array}{l}\text { Peningkatan gizi ikan untuk } \\
\text { menghindari stunting }\end{array}$ & T3 & $\begin{array}{l}\text { Produk yang berkualitas sehingga } \\
\text { terstandar ekspor }\end{array}$ \\
\hline $\mathrm{O} 4$ & $\begin{array}{l}\text { Produksi perikanan tangkap yang } \\
\text { meningkat secara signifikan }\end{array}$ & $\mathrm{T} 4$ & $\begin{array}{l}\text { Desain dan kemasan yang menarik } \\
\text { dan terstandar }\end{array}$ \\
\hline
\end{tabular}

Tabel 2. Matriks Evaluasi Faktor Strategis Internal Table 2. Evaluation Matrix of External Strategic Factor

\begin{tabular}{|l|c|c|c|}
\hline Kekuatan & Bobot & Rating & Skor \\
\hline $\begin{array}{l}\text { Bahan baku melimpah dan } \\
\text { berkualitas }\end{array}$ & 0,11 & 4 & 0,44 \\
\hline $\begin{array}{l}\text { Jarak tempuh bahan baku, tempat } \\
\text { produksi dan pemasaran yang } \\
\text { dekat }\end{array}$ & 0,09 & 2 & 0,18 \\
\hline $\begin{array}{l}\text { Kandungan nutrisi bahan baku } \\
\text { yang bermanfaat bagi tubuh }\end{array}$ & 0,10 & 3 & 0,30 \\
\hline $\begin{array}{l}\text { Potensi ekspor produk tinggi } \\
\text { Hubungan yang baik antara } \\
\text { sektor dan non pemerintah }\end{array}$ & 0,10 & 3 & 0,30 \\
\hline Kelemahan & Bobot & Rating & Skor \\
\hline $\begin{array}{l}\text { Fluktuasi hasil tangkapan yang } \\
\text { musiman pada ikan cakalang }\end{array}$ & 0,11 & 4 & 0,44 \\
\hline $\begin{array}{l}\text { Belum optimal pemasaran produk } \\
\text { di media sosial }\end{array}$ & 0,11 & 4 & 0,44 \\
\hline Belum optimal promosi produk & 0,11 & 4 & 0,44 \\
\hline $\begin{array}{l}\text { Promosi melalui online belum } \\
\text { optimal }\end{array}$ & 0,11 & 4 & 0,44 \\
\hline Total Skor & 1 & & 3,18 \\
\hline
\end{tabular}


PELAGICUS: Jurnal IPTEK Terapan Perikanan dan Kelautan

Volume 2 Nomor 2: 107-116, Mei 2021

Tabel 3. Matriks Evaluasi Faktor Strategis Eksternal Table 3. Evaluation Matrix of External Strategic Factor

\begin{tabular}{|l|c|c|c|}
\hline Peluang & Bobot & Rating & Skor \\
\hline $\begin{array}{l}\text { Peningkatan konsumsi ikan pada } \\
\text { masyarakat }\end{array}$ & 0,11 & 3 & 0,34 \\
\hline $\begin{array}{l}\text { Pengolahan ikan yang lebih variatif } \\
\text { Peningkatan gizi ikan untuk } \\
\text { menghindari stunting }\end{array}$ & 0,13 & 4 & 0,50 \\
\hline $\begin{array}{l}\text { Produksi perikanan tangkap yang } \\
\text { meningkat secara signifikan }\end{array}$ & 0,13 & 4 & 0,34 \\
\hline Ancaman & Bobot & Rating & Sk or \\
\hline \begin{tabular}{l} 
Fluktuasi harga ikan cakalang \\
\hline Branding yang menarik
\end{tabular} & 0,11 & 3 & 0,34 \\
\hline $\begin{array}{l}\text { Produk yang berkualitas sehingga } \\
\text { terstandar ekspor }\end{array}$ & 0,10 & 2 & 0,50 \\
\hline $\begin{array}{l}\text { Desain dan kemasan yang menarik } \\
\text { dan terstandar }\end{array}$ & 0,11 & 3 & 0,20 \\
\hline Total Sk or & 1 & & 3,05 \\
\hline
\end{tabular}

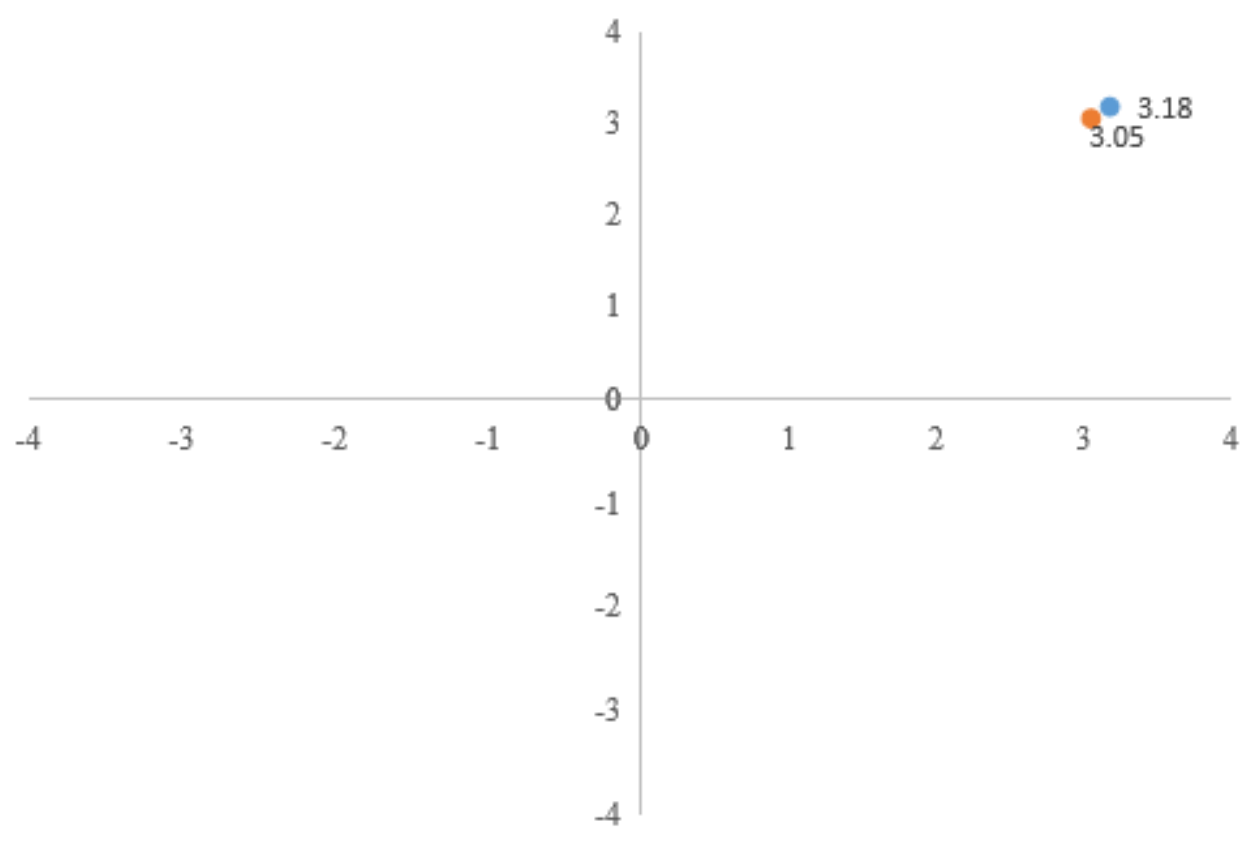

Gambar 1. Matriks SWOT

Figure 1. SWOT Matrix

\section{BAHASAN}

\section{Identifikasi Faktor Internal}

Berdasarkan hasil Penelitian di UKM Frozen seas, berikut ini faktorfaktor internal yang dapat di identifikasi antara lain:

\section{Bahan baku}

Bahan baku merupakan faktor yang paling penting untuk menghasilkan produk berkualitas. Ikan cakalang termasuk ikan musiman sehingga mempengaruhi harga bahan baku yang 
fluktuaktif berdampak pada harga jual produk. Bahan baku ikan cakalang diperoleh dari PT Perikani yang telah mendapatkan sertifikasi HACCP dan BPOM.

a) Produk ikan cakalang asap telah mendapatkan label halal MUI dan izin P-IRT. Hal ini merupakan jaminan produk yang berkualitas dan menambah nilai jual produk untuk mempromosikan produk. Berikut ini MUI. 24030005281018 dan izin P-IRT no 2-02-71.72-22-0142-23.

b) Pemasaran ikan cakalang asap belum optimal karena pemasaran online hanya melalui facebook dan instagram sedangkan pemasaran offline dengan memasarkan pada outlet pribadi sebanyak 2 tempat dan konsinyasi dengan toko oleh oleh di Manado..

c) Manajemen UKM Frozen seas menerapkan tertib administrasi dengan pembukuan yang baik dan pengelolaan keuangan ditangani oleh internal keluarga. Manajemen yang baik ini diantaranya membuat pembukuan pemasukan dan pengeluaran setiap bulan, disiplin membayarkan tagihan, dan punya alokasi anggaran dalam keadaan darurat.

d) Permodalan : modal pribadi dan pinjaman dari BANK.

e) Infrastruktur berkaitan dengan Unit Pengolahan Ikan yang cukup lengkap yaitu terdapat sarana penyimpanan bahan baku, sarana penyimpanan produk jadi, tempat penjualan produk yang baik dan cukup memadai dengan adanya ruangan tertutup serta menggunakan pendingin ruangan.

\section{Identifikasi Faktor Eksternal}

Analisis PEST (Politik, Ekonomi, Sosial Budaya dan Teknologi)

Identifikasi faktor eksternal dengan menggunakan analisis PEST. Berikut ini ada 4 faktor PEST yang perlu dianalisis secara menyeluruh:
1). Faktor politik, kebijakan-kebijakan pemerintah pusat dan pemerintah daerah mempunyai pengaruh pada UKM. Pemerintah telah mengeluarkan Undang-undang Nomor 20 Tahun 2008 tentang Usaha Mikro, Kecil dan Menengah (UMKM). Pada pasal 7 ayat (1) berbunyi : Pemerintah dan pemerintah daerah menumbuhkan Iklim Usaha dengan menetapkan peraturan perundang-undangan dan kebijakan yang meliputi aspek: 1. Pendanaan 2. Sarana dan Prasarana 3. Informasi Usaha 4. Kemitraan 5. Perizinan Usaha 6. Kesempatan berusaha 7. Promosi Dagang 8. Dukungan Kelembagaan (Komarudin, 2014). Menurut Purba (2018) menyatakan bahwa peran pemerintah seharusnya hadir diberbagai lini sebagai fasilitator, regulator dan katalisator dalam pemberdayaan UMKM. Pemerintah sebagai fasilitator yang berperan dalam memberikan modal, pemasaran maupun pelatihan. Peran pemerintah sebagai regulator dengan membuat kebijakan-kebijakan untuk mempermudah usaha UMKM dalam mengembangkan usahanya. Selain itu, pemerintah sebagai katalisator yang berperan untuk mempercepat proses perkembangan dari UMKM.

2). Faktor ekonomi. Ikan cakalang mengalami fluktuasi harga yang bergantung pada musim penangkapan. Hal ini berdampak pada ketersedian bahan baku dan harga produk.

3). Faktor sosial. Kebiasaan masyarakat Bitung dalam mengkonsumsi ikan sangat tinggi, sehingga kebutuhan konsumsi ikan cenderung stabil.

4). Faktor teknologi. Teknologi pengasapan yang didesain dengan inovasi oleh pemilik sehingga produknya cakalang asap sesuai dengan keinginan. 


\section{Bauran Pemasaran}

Menurut Kotler dan Armstrong (2010) bahwa variabel-variabel dalam bauran pemasaran dikelompokkan menjadi produk, harga, tempat, promosi. Perumusan strategi pemasaran diperoleh melalui analisis lingkungan internal dan lingkungan eksternal (Karinda dkk, 2018). Lingkungan internal adalah lingkungan organisasi yang berada dalam organisasi dan secara normal memiliki implikasi langsung dan khusus pada perusahaan (Setyowati, 2015). Strategi pemasaran yang ditinjau pada UKM Frozan Seas meliputi : produk, harga, promosi, distribusi.

\section{Produk}

UKM Frozen seas telah bekerjasama dengan PT. PERIKANAN NUSANTARA sebagai supplier bahan baku ikan cakalang. Bahan baku ikan cakalang didapatkan dari
PT. PERIKANAN NUSANTARA sudah mempunyai kualitas ekspor. Produk cakalang asap UKM Frozen seas merupakan produk yang dibuat dari ikan cakalang yang mempunyai kualitas baik. Produk cakalang asap UKM Frozen seas telah memperhatikan standar pangan dan mendapatkan sertifikat MUI dan P-IRT yang aman untuk dikonsumsi. UKM Frozen seas mengemas tuna asap swir menggunakan kemasan plastik PVC $0,3 \mathrm{~mm}$ yang sudah diberi label. Kemasan produk cakalang asap swir berisi informasi antara lain nama produk "cakalang asap", komposisi produk, berat bersih, berat bersih, nama dan alamat produksi, keterangan halal dan masa kadaluwarsa yang ditunjukkan pada Gambar 2. Pemberian label produk cakalang asap swir ini sudah sesuai dengan UU Undang-Undang RI No. 7 tahun 1996 tentang Pangan pada pasal 30 ayat 2 .

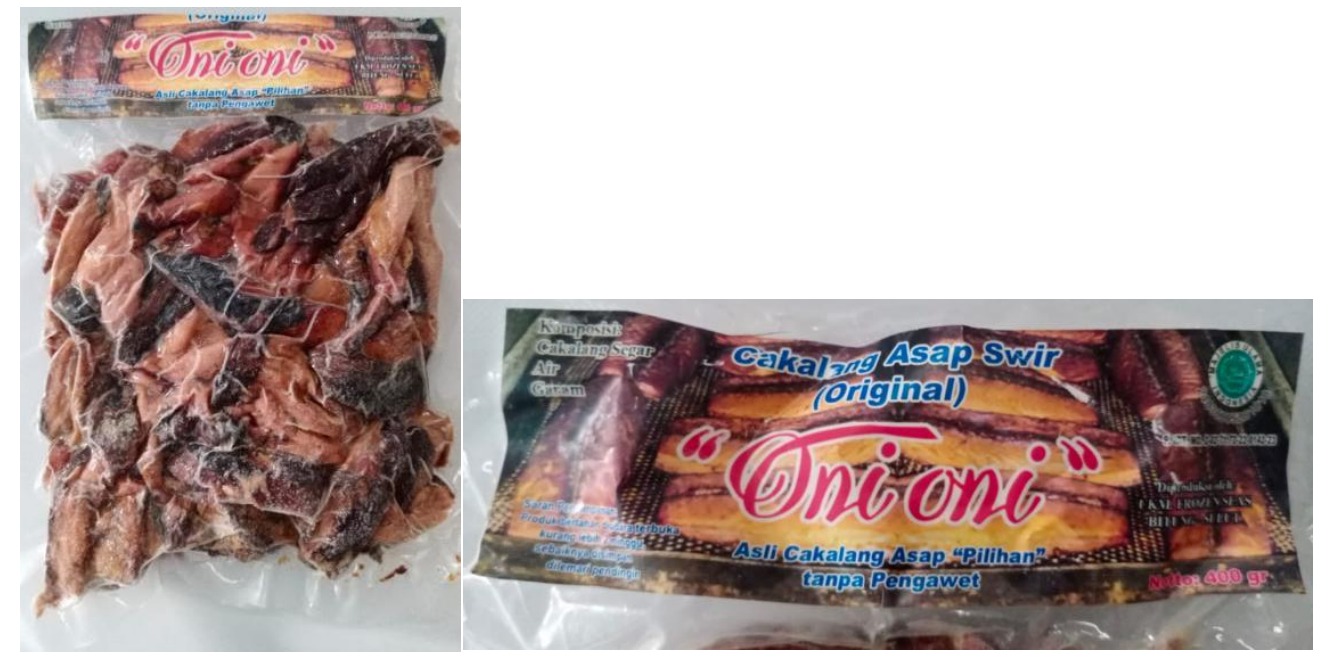

Gambar 2. Kemasan Cakalang Asap Swir Figure 2. Swir Smoked Skipjack tuna packaging

\section{Harga}

Produk tuna swir asap mempunyai berat bersih $400 \mathrm{~g}$ dengan harga Rp. $35.000,00$. Penetapan harga produk ini dilakukan oleh pemilik usaha. Penetapan harga ini berdasarkan pada harga bahan baku dan biaya produksi. Menurut Setiyorini dkk. (2018) bahwa penetapan harga didasarkan pada harga bahan baku, upah tenaga pengolah, baik utama 
maupun pendamping, biaya operasional dan margin keuntungan yang disesuaikan dengan harga produk sejenis dari kompetitor. Menurut Engel dan Blackwell (2004) bahwa tujuan terhadap penentuan harga diantaranya dapat berupa meningkatkan penjualan, mencapai laba maksimum, mempertahankan market share, mempertahankan stabilitas harga.

\section{Promosi}

Promosi merupakan salah satu cara komunikasi pemasaran yang berupa aktivitas pemasaran yang bertujuan menyebarkan informasi, mempengaruhi, serta meningatkan pasar sehingga produknya dapat diterima dan dibeli oleh masyarakat (Tjiptono, 1997). Promosi produk UKM Frozen seas dilakukan dengan beberapa cara, diantaranya : (1) Pemasaran dari mulut ke mulut (word of mouth) yang dilakukan oleh konsumen yang suka dan puas dengan produk cakalang asap UKM Frozen seas, (2) Direct Selling dengan mengikuti seminar dan pameran di wilayah Bitung maupun Manado, (3) Internet, UKM Frozen seas mempunyai facebook, (4) menerima lokasi praktek maupun magang untuk taruna taruni Politeknik Kelautan dan Perikanan Bitung.

\section{Distribusi}

Distribusi merupakan salah satu hal yang penting dan berdampak pada penjualan produk. UKM Frozen seas melakukan kerjasama dengan distributor barang untuk memasarkan ikan cakalang asap di Bitung. UKM ini menggunakan strategi distribusi selektif karena penyaluran distribusi produk barang maupun jasa pada wilayah pemasaran tertentu dengan mengoptimalkan beberapa distributor pada satu daerah. Saluran distribusi adalah serangkaian organisasi yang saling tergantung dan terlibat dalam proses untuk menjadikan suatu barang atau jasa siap untuk digunakan atau untuk dikonsumsi
(Kotler, 2002). Saluran distribusi UKM Frozen seas meliputi : Produsen $\rightarrow$ konsumen.

\section{Analisis Matriks SWOT}

Analisis SWOT (Kekuatan, kelemahan, peluang dan ancaman) digunakan untuk menganalisis produk ikan cakalang asap. Analisis SWOT produk ikan cakalang asap ditunjukkan pada tabel 1 dan gambar 1. Analisis SWOT digunakan untuk mendapatkan strategi pemasaran yang optimal dan tepat. Dari analisis SWOT, diidentifikasi empat jenis strategi: kekuatan - peluang (gunakan kekuatan untuk memanfaatkan peluang), kekuatan-ancaman (gunakan kekuatan untuk mengurangi ancaman), kelemahan - peluang (kurangi kelemahan dengan memanfaatkan peluang) dan kelemahan - Ancaman (mengurangi kelemahan dengan mencegah ancaman). Analisis SWOT menggunakan data kinerja lingkungan dan evaluasi ekonomi.

SO:Membangun kerjasama dengan perusahaan untuk mendapatkan bahan baku dan produk yang berkualitas.

Pada gambar 1 menunjukkan bahwa hasil analisis SWOT pada kuadran 1 yang berhubungan dengan Strength (S) dan Opportunity (O). Ikan cakalang merupakan hasil tangkapan ikan yang melimpah di Bitung. Masyarakat Bitung mempunyai tingkat konsumsi ikan yang tinggi. Hasil tangkapan ikan yang melimpah berdampak pada persediaan bahan baku. Bahan baku yang melimpah akan berdampak persediaan produk. Penanganan ikan yang tepat menghasilkan bahan baku ikan yang berkualitas. Kerjasama perusahaan yang menyediakan ikan perlu pemilihan yang tepat yaitu : perusahaan yang sudah menerapkan GMP dan SSOP sehingga sudah terstandar HACCP. UKM Frozen seas sudah melakukan kerjasama dengan PT PERIKANI. Hal ini membuktikan bahwa bahan baku dan produk yang berkualitas menyebabkan perusahaan 
dapat menghasilkan produk yang berkualitas pula. Produk yg berkualitas ini akan dapat dijual dengan maksimal apabila didukung dengan strategi pemasaran yang menarik dan bersaing. Strategi pemasaran dengan e-commerce merupakan pilihan yang efektif di era modern.

ST (Diferensiasi pengemasan yang ramah lingkungan, taste dan harga yang murah)

Diferentiation merupakan hal yang perlu dilakukan pada UKM untuk memenuhi target pemasaran. Berdasarkan analisis SWOT maka strategi pemasaran yang tepat pada UKM ini adalah cost leadership karena target pemasaran saat ini yaitu kalangan menengah.. Cost leadership merupakan salah satu strategi diferensiasi. Untuk mengatasi ketatnya persaingan pada UKM maka diperlukan target segmen lain. Pada pandemic COVID-19 ini health lifestyle merupakan tuntutan manusia untuk memilih gaya hidup sehat dan bergizi. Target segemen lain yaitu UKM dapat membidik masyarakat yang menerapkan gaya hidup sehat yang berasal dari kalangan masyarakat menengah ke atas. Oleh karena itu, perlu adanya informasi nilai gizi kandungan ikan cakalang asap pada kemasan.

WT (Menindaklanjuti tentang penerapan Teknologi Pengasapan yang efektif dan efisien terhadap peningkatan kandungan nutrisi ikan)

Perkembangan teknologi pengolahan yang berkembang pesat sehingga berdampak pada produk produk makanan yang bervariasi. Teknologi pengasapan ikan yang baik akan menghasilkan produk ikan cakalang asap yang berkualitas. Indikasi ikan asap yang baik ditandai dengan kesesuaian standar SNI Ikan Asap Baru SNI 2725:2013. Dengan demikian, dibutuhkan teknologi pengasapan ikan cakalang yang tepat agar menghasilkan produk ikan cakalang asap yang berstandar SNI.
WO (Mencantumkan informasi kandungan gizi pada kemasan, menambah pasar dengan kerjasama pihak terkait)

Informasi analisis kandungan gizi pada kemasan merupakan salah satu keunggulan produk. Pada masa pandemi COVID-19 ini, konsumen harus selektif dalam memilih makanan yang bergizi untuk peningkatan imun. Oleh karena itu, informasi kandungan gizi juga mempengaruhi peningkatan target pemasaran. Selain itu, perlu adanya memperluas jaringan kerjasama dengan instansi terkait.

\section{SIMPULAN}

Berdasarkan penelitian untuk merumuskan strategi pemasaran penjualan produk ikan cakalang asap menggunakan metode analisis SWOT dengan mempertimbangkan faktor internal dan eksternal. Oleh karena itu, berdasarkan faktor internal dan eksternal maka diperlukan beberapa strategi diantaranya kerjasama dengan perusahaan untuk mendapatkan bahan baku dan produk yang berkualitas; diferensiasi pengemasan yang ramah lingkungan, taste dan harga yg murah; penerapan teknologi pengasapan yang efektif dan efisien terhadap peningkatan kandungan nutrisi ikan; informasi kandungan gizi pada kemasaan, menambah pasar dengan kerjasama dengan pihak terkait.

\section{DAFTAR PUSTAKA}

Engel, J; Blackwell, R. (2004). Consumer Behavior. Yogyakarta: Dryden Press Chicago. Andi

Setiyorini, E. S., Noorachmat, B. P., \& Syamsun, M. (2018). Strategi Pemasaran Produk Olahan Hasil Perikanan pada UMKM Cindy Group. Jurnal Manajemen IKM, 13 (1), 19-28. 
Faradizza, D. M., Andaki, J. A., \& Pangemanan, J, F. (2019). Analisis Usaha Perikanan Tangkap Cumi-Cumi Pada Nelayan Tradisional di Kelurahan Motto Kecamatan Lembeh Utara Kota Bitung. Akulturasi, 7 (1), 1155-1160.

Firdaus, M. (2018). Profil Perikanan Tuna dan Cakalang di Indonesia. Buletin Ilmiah "MARINA" Sosial Ekonomi Kelautan dan Perikanan, 4 (1), 23-32.

Pramana, P. E., Pangemanan, S., \& Egeten, M. (2017). Kebijakan Pemerintah Kota Dalam Menggali Pendapatan Asli Daerah Di Sektor Perikanan Kota Bitung. Jurnal Eksekutif, 2 (2), 1-13.

Supriana, A., Hascaryo, B., Wisudo, S. H., Baskoro, M., \& Nikijuluw, V. P. H. (2014). Model Rantai Nilai Pengembangan PerIkanan Tuna, Tongkol dan Cakalang di Indonesia. Jurnal Pengolahan Hasil Perikanan Indonesia, 17 (2), 144-155.

Sarwoko, E. (2017). Strategi Pertumbuhan Usaha Kecil Menengah (UKM). Jurnal Ekonomi Moderinisasi, 13 (1), 46-52.

Tjiptono, F. (1997). Strategi Pemasaran. Edisi Kedua. Yogyakarta: Penerbit Andi.

Karinda, M. V. A., Mananeke, L., Roring, F. (2018). Pengaruh Strategi Pemasaran dan Inovasi Produk Terhadap Kinerja Pemasaran Produk Indihome Pada PT Telkom Area Tomohon. Jurnal EMBA, 6 (3), 1568 - 1577.

Kementerian Kelautan dan Perikanan. 2015. Rencana Pengelolaan Perikanan Tuna, Cakalang dan Tongkol. Direktorat Sumber daya Ikan Direktorat Jenderal PerIkanan Tangkap. KKP. Jakarta.

Komarudin, A. (2010). Politik Hukum Integratif UMKM. Jakarta: RM Books.
Kotler. (2002). Manajemen Pemasaran, Jilid 1, Edisi Milenium. Jakarta: Prehallindo.

Kotler, P., \& Armstrong, G. (2010). Principles of Marketing, edisi 13. United States of America: Pearson.

Li, X. (2009). Entrepreneurial Competencies as an Entrepreneurial Distinctive: An Examination of the Competency Approach in Defining Entrepreneurs. Theses. Institutional Knowledge at Singapore Management University.

Riyanto, S. (2018). Analisis Pengaruh Lingkungan Internal dan Eksternal Terhadap Keunggulan Bersaing dan Kinerja Usaha Kecil Menengah (UKM) di Madiun. Jurnal Manajemen Bisnis dan Inovasi, 5 (3), 159-168.

Setyowati, N. W. (2015). Pengaruh Lingkungan Eksternal dan Lingkungan Internal Terhadap Keunggulan Bersaing Pada Industri Kecil dan Menengah di Bandung, Jawa Barat. ESENSI Jurnal Bisnis dan Manajemen, 5 (1), 9-26.

Sulistiana, O., Kendek, M., Nurwahidah, \& Rahman, S. (2018). Analisis Kehandalan Pelabuhan Bitung Dalam Menyukseskan Program Tol Laut. Jurnal VENUS, 06 (11), 31-44.

Sutardjo, S.C. 2014. Kebijakan Pembangunan Kelautan dan Perikanan ke Depan Developmen Policy of Marine And Fisheries. Jurnal Kebijakan Perikanan Indonesia, 6(1), 37-42.

Purba, G. M. (2018). Peran Pemerintah Daerah Dalam Memberdayakan UMKM di Kota Semarang (Studi Kasus Kampung Batik Kota Semarang). Journal of Politic and Government Studies, 7 (4), 191-200.

Komarudin, A. (2010), Politik Hukum Integratif UMKM, Jakarta: RM Books. 